\title{
Antimalaria Medicine and Its Mechanism : A Review
}

\author{
Nor Latifah*,1, Anas Subarnas², Anis Yohana Chaerunisaa ${ }^{1}$ \\ ${ }^{1}$ Department of Pharmaceutics and Pharmaceutical Technology, Universitas Padjadjaran, Jatinangor 45363 \\ ${ }^{2}$ Department of Pharmacology and Clinical Pharmacy, Universitas Padjadjaran, Jatinangor 45363 \\ *email: nor18001@mail.unpad.ac.id
}

(Submit 24/1/2020, Revisi 28/1/2020, Diterima 30/1/2020)

\begin{abstract}
Malaria is a deadly disease caused by Plasmodium infection that is spread by female Anopheles. Malaria is a serious and deadly disease due to Plasmodium infection which is spread by female Anopheles mosquitoes. Among the five Plasmodium species, the most common species attacking humans are the Plasmodium falciparum and Plasmodium vivax species. Decreased sensitivity resulting in continuous and inadequate treatment, causing parasitic mutations, other than that allegedly originating from resistant areas. The purpose of this paper is to find out some anti-malaria drugs and the mechanism of action used in Indonesia based on references from the current development of anti-malaria drugs. While the benefits are providing information about antimalarial drugs and the mechanism of action in the use of drugs in Indonesia for malaria. Treatment of malaria is classified into 3, namely: classification of malaria drugs based on the workings of drugs in the Plasmodium life cycle, classification of antimalarial drugs based on the chemical structure of the drug, and classification of antimalarial drugs based on the workplace of the drug in the Plasmodium subcellular organelle.
\end{abstract}

Keywords: Malaria, Plasmodium, antimalarial, mechanism

\section{Outline}

- Introduction

- Discussion

- Conclusion

- Acknowledgement

- References

\section{Introduction}

Malaria is a serious and deadly disease caused by Plasmodium falciparum infection which is spread by Anopheles mosquitoes ${ }^{1}$. Malaria also remains an infectious disease, infecting millions of people, especially in the tropics. Among the five Plasmodium species, the most common species attacking humans are Plasmodium falciparum and Plasmodium vivax species ${ }^{2}$. Despite the increase in its impact, malaria will continue to affect human health. The updated forecasts show that 212 million cases occur by 2015 , which caused 429,000 deaths, most occur in children under 5 in Africa ${ }^{3}$. 
Decreased sensitivity resulting in continuous and inadequate treatment, causing parasitic mutations, other than that allegedly originating from resistant areas. In the last thirty years, Plasmodium falciparum has been resistant to existing anti-malaria drugs. Antimalarial drug resistance has also occurred against Plasmodium vivax and has been reported from Papua New Guinea, India, Myanmar, and Indonesia so that malaria treatment must be adapted to the geographical conditions of each country ${ }^{4}$.

Efforts to eradicate malaria were severely hampered due to the development of Plasmodium falciparum resistance to current antimalarial drugs such as chloroquine, sulfadoxine-pyrimethamine, amodiaquine, and kinin. The mechanism of resistance is due to genetic mutations that occur naturally in malaria parasites that provide benefits for the parasite to survive ${ }^{5}$.

The purpose of this paper is to discuss some antimalaria drugs and the mechanism of action of drugs used in Indonesia based on references from the current development of antimalaria drugs.

\section{Discussion}

\section{Malaria Life Cycle}

The malaria life cycle consists of 2 cycles, namely the exogenous sexual phase (sporogony) in the body of the mosquito and the asexual (schizo) phase in the body of the intermediate/human host6.

\section{Sexual Phase Exogenous (Sporogoni) in Mosquito Body}

Mengingesti female Anopheles mosquito erythrocytes containing microgametes and macrogametes of patients. In the mosquito's body mating occurs between microgametes and macrogametes producing zygotes. This mating occurs in the mosquito stomach. The zygote develops into an ookinete, then enters the wall of the stomach of the mosquito to develop into an oocyst, after the oocysts mature and rupture, out of the sporozoite that moves to the mosquito's salivary gland and is ready to be transmitted to humans

\section{Asexual Phase (Skizon) in the Body of Intermediary/Human Hospes}

\section{Hepatic Cells Cycle (Skizon Eksoritrositik)}

When biting the humans, the sporozoites of Anopheles enter the bloodstream for $1 / 2$ to 2 hours then head to the liver to multiply. This sporozoite quickly infects the liver cells and then develops into the exoerythrocytic schizont. The exoerythrocytic schizont contains up to 30,000 merozoites. Liver cells infected with exoerythrocytic schizont rupture and release mature merozoites into the bloodstream. 


\section{Erythrocytes Cycle (Skizon Eritrositik)}

Merozoites are released from erythrocytes infects liver cells, then evolved into reform, then trophozoite, and eventually become schizonts. Erythrocytes containing schizont rupture and release merozoites to infect other erythrocytes.

\section{Malaria Symptoms And Parasite Mechanisms In Infecting Eritrosits}

\section{Symptoms of Malaria}

Clinical manifestations of malaria depends on the immunity of patients and the high transmission of malaria infection, while the lightness or heaviness of infection will be affected by Plasmodium species, age, area of origin of the infection, state of health, nutrition consumed, the alleged genetic constitution, as well as chemoprophylaxis and treatment earlier ${ }^{6}$.

\section{Paroxysmal}

A condition where the attack occurs very often and in a short time, such as cold, headache, diarrhea, vomiting, nausea, anorexia, chills, cramps, stiffness, fever for 48 hours, fever at body temperature $\geq 37,5^{\circ} \mathrm{C}$, hepatomegaly, splenomegaly 7 .

Clinical manifestations of symptoms of severe malaria

A condition where the attack is more severe, such as respiratory distress, severe anemia, collapse, hyperpyrexia, persistent vomiting, hypoglycemia, hypotension, coma, convulsions, hemoglobinuria6,7.

\section{The Mechanism of Plasmodium falciparum in Infecting Erythrocytes}

The occurrence of Plasmodium falciparum infection in humans occurs when sporozoite is released from the salivary gland of female Anopheles mosquitoes (containing malaria parasites). It then enters the blood cells and liver tissue. The life cycle of the malaria parasite forms the tissue sizone stage in liver cells (exoerytrocyther stage). After liver cells rupture, then release merozoites that enter the erythrocytes to form the sizone stage in erythrocytes (erythrocyte stage). The shape of the young troposite until the mature sizone causes the erythrocytes to break out and out of merozoites. Most Merozoites reenter the erythrocytes and a small portion form male gametocytes.

The cycle of female Anopheles mosquitoes. Female Anopheles is infected by female malaria mosquitoes and continue their life cycle in the mosquito body (sporogony stage). Inside the mosquito's stomach, there is a marriage between gamete cells called zygotes. The zygote will turn into an ookinete, and turn into an oocyst in mosquito's stomach. The mature form will break and secretes sporozoites that enter the mosquito's salivary gland ${ }^{8}$. 
Antimalaria Medicines And Mechanism of Its Work

Classification of Malaria Drugs Based on How the Drug Works on the Plasmodium Life Cycle

Blood Schizontoside Antimalarial Medicine

It is the one who attacks the Plasmodia that live in the blood. This type of antimalarial is for prevention and ending clinical attacks ${ }^{6}$, such as primaquine ${ }^{9}$, artemisinin, dihydroartemisinin ${ }^{10}$, chloroquine, mepacrine, amodiaquine, mefloquine, quinine, quinidine, halofantrine and tetracycline, fluoroquinolone, and erythromycin, erythromycin, erythrome ${ }^{11,12}$.

Chloroquine is one of the autophagy inhibitors antimalarial drugs ${ }^{12,13}$. Chloroquine, a 4aminoquinoline drug, is widely used throughout the world where malaria is endemic. It has been the most effective and cheapest antimalarial for several decades, and still recommended to treat Plasmodium vivax infections. Indeed, chloroquine has a quick onset reaction, with low toxicity ${ }^{12,14}$.

The mechanism of chloroquine is the inhibition of the formation of $\beta-43$ hematin in the vacuole of the parasite ${ }^{12,14}$. The mechanism of action of this drug is unclear because it is alkaline drug can achieve high concentrations in food vacuoles from parasites and increase its $\mathrm{pH}$. Chloroquine suppresses the enzyme heme-polymerase from the parasite which functions to change the heme toxin into non-toxic hemozoin that results from the accumulation of toxic heme in the body of the parasite. Chloroquine also inhibits the process of nucleic acid biosynthesis ${ }^{4}$.

Mefloquine is a methanol quinoline, having a similar structure with quinine. This is a strong and long-acting blood schizontocide, and effective in killing malaria parasites including Plasmodium falciparum which is resistant to chloroquine, and quinine ${ }^{12,14}$.

Tissue Antimalarial Medication

It is the one that kills Plasmodia in the exoerythrocytic phase in the liver, preventing the invasion of Plasmodia in blood cells ${ }^{6}$, such as pyrimethamine and primaquine. This group of drugs can prevent relapse in Plasmodium vivax infection ${ }^{15}$.

Pyrimethamine is a weak base drug with water solubility $\sim 40 \mu \mathrm{g} / \mathrm{ml}$ at $25^{\circ} \mathrm{C}$. Pyrimethamine has pKa 7 at $20^{\circ} \mathrm{C}$ and $\log P 2.7$. Even though the base is weak, pyrimethamine release at gastric $\mathrm{pH}$ $(\sim 1-2)$ does not reach $100 \%$ even after 3 hours $^{16}$.

Primaquine (PMQ), 8-aminoquinoline, is antimalarial drugs that have the advantage of preventing recurrence in Plasmodium vivax and Plasmodium ovale, and including powerful drugs against gametocytes from Plasmodium falciparum infection. The disadvantage of $P M Q$ is the acute hemolytic toxicity to people having glucose-6-phosphate dehydrogenase (G6PD) deficiency ${ }^{17}$. The mechanism of action of this drug is not yet clear, it is suspected that this drug works by producing reactive oxygen or competing with electron transport in parasitic bodies. Primakuin is well absorbed after oral administration and is rapidly metabolized. Half time \pm 6 hours. Metabolites from primaquine are oxidative substances and can cause hemolysis in sensitive patients ${ }^{4}$. 


\section{Gametocide Antimalarial Medication}

It is killing the stage of gametocytes in the blood ${ }^{6}$, gametocide works by destroying the sexual form of all species of Plasmodium malaria in the blood so as to prevent the transmission of parasites to the body of mosquitoes like Primakuin ${ }^{4}$.

\section{Antimalarial Drug Sporontocide}

Inhibiting the development of further gametocytes in the body of mosquitoes that suck human blood, so that there is no transmission, such as the drug groups primaquine and proguanil ${ }^{15}$. Proguanil is one of the antimalarial prophylactic drugs usually taken simultaneously with other antimalarial drugs, namely atovaquone or chloroquine. The cytochrome P450 enzyme converted in the liver, into 4-chlorophenyl-1-biguanide (CPB) and active metabolite cycloguanil (CG). Proguanil is a phenylbiguanide group and has a striking structural similarity to the 5hydroxytryptamine 3 (5-HT3) receptor widely known as agonistmeta-chlorophenyl biguanide $(\mathrm{Mcpbg})^{18}$.

Classification of Antimalarial Drugs Based on the Structure of Drug Chemistry ${ }^{15}$

Table 1: Antimalaria Classification Drug

\begin{tabular}{|c|c|}
\hline Antimalarial Drug Classification & Drug Name \\
\hline Aryl aminoalkohol & $\begin{array}{l}\text { Kuinolon metanol kinina \& meflokuin dan } \\
\text { phenanten metanol halofantrin }\end{array}$ \\
\hline 4-aminokuinolon & Klorokuin dan amodiakuin \\
\hline Sulfanes & $\begin{array}{l}\text { Di aminophenil sulfone \& sulfadoksin, sulfalene } \\
\text { dan kontrimoksasol }\end{array}$ \\
\hline Biguanida & Proguanil/ klorguanida dan klrorproguanil \\
\hline 8-aminokuinolon & Primakuin \\
\hline Antibiotik & Tetrasiklin, doksisiklin, clindamisin \\
\hline \multirow[t]{7}{*}{ Obat antimalaria peroxide } & Artemisinin \\
\hline & Artemisinin \\
\hline & Artemether \\
\hline & Dihydroartemisinin \\
\hline & Arteether \\
\hline & Artesunate \\
\hline & Artelinic acid \\
\hline Diaminopirimidin & Pirimetamin \\
\hline Alkaloids cinchona & Kinina \\
\hline
\end{tabular}

Classification of Antimalarial Drugs Based on Medication Workplace in Subcellular Organelles Plasmodium

Group 4-aminocinolin Drug

The 4-aminoquinoline chloroquine drug (Figure 1) has been widely used in malaria treatment. Chloroquine expected to be trapped in parasitic vacuoles, where chloroquine inhibits the biocrystallization of $\beta$-hematin. 
This is a result of the nature of the vacuole, where chloroquine becomes 'trapped' in the form of an impermeable membrane that is definitely protected. Chloroquine then complexes with heme free, leading to the heme accumulation and ultimately, parasitic death ${ }^{19}$.

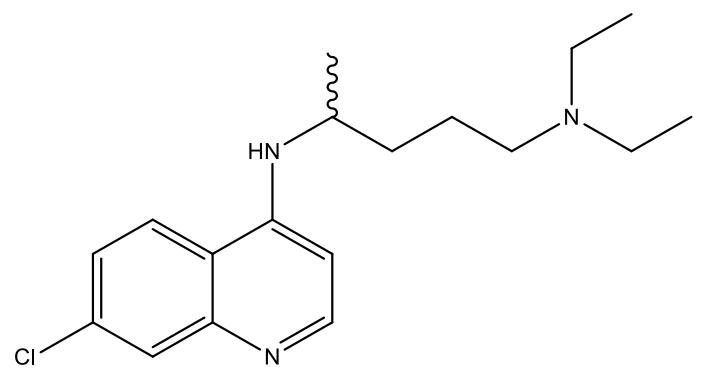

Fig.1 Chloroquine ${ }^{19}$.

Antibiotic

Doxycycline and tetracycline have simple antimalarial activity against Plasmodium vivax or Plasmodium falciparum. Doxycycline has now replaced tetracycline for use in combination with quinine against Plasmodium falciparum because of its therapeutic advantages of twice-daily doses and low costs (US $\$ 3.14 / 100$ generic capsules in Indonesia) ${ }^{20}$.

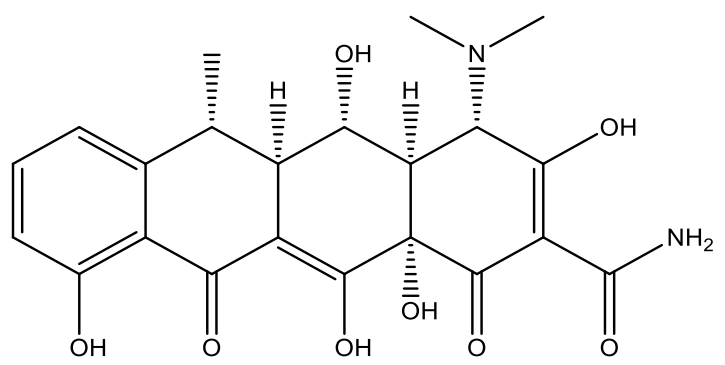

Fig. 2 Doxycycline 21

Antimalarial Drug Sulfadoxine and Pyrimethamine

Sulfadoxine and pyrimethamine are blood schyzontocides that work slowly and are more effectively active against Plasmodium falciparum than Plasmodium vivax. They inhibit dihydrofolate reductase from Plasmodia, which is important in etrahydrofolate biosynthesis. Sulfadoxine-pyrimethamine is also called the group of anti-folate drugs because it works by blocking the two pathways of the formation of folate in the body of the parasite. Sulfadoxine inhibits the use of para-aminobenzoic acid (PABA) by inhibiting the enzyme dihydropteroate synthase (DHPS). Pyrimethamine inhibits the enzyme dihydrofolate reductase (DHFR) from Plasmodium thereby blocking the synthesis of thymine and purines which are important ingredients for DNA synthesis and cell multiplication ${ }^{4}$.

The half-life of Sulfadoxine and Pyrimethamine is $\sim 169$ hours and $\sim 111$ hours $\alpha / \beta$ Arteether is a CYP3A4/5 substrate, whereas sulfadoxine-pyrimethamine has no interaction with CYP3A4/522. 

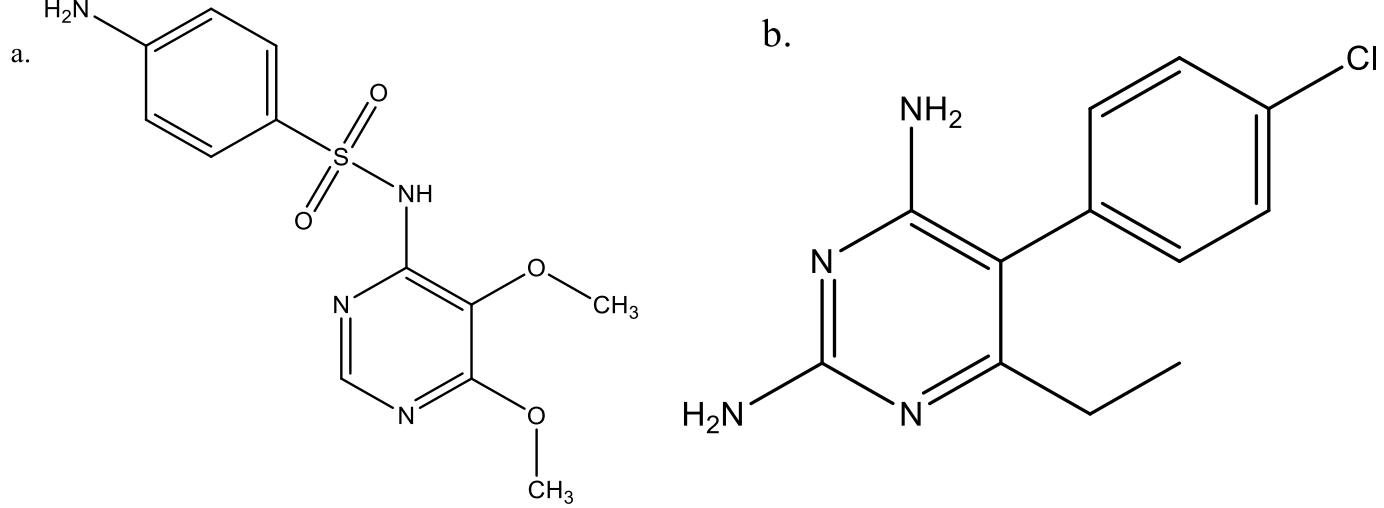

Fig. 3 a. Sulfadoxine dan b. Pyrimethamine ${ }^{23}$

\section{Drug Generation From Artemisinin}

Artemisinin is a sesquiterpene molecule contained sesquiterpen molecules including hydrogen, carbon, and oxygen but does not have a nitrogen atom and has advantages in the treatment of several drug-resistant strains of Plasmodium falciparum (MDR). Artemisinin has an antimalarial working mechanism that is different from other antimalarial drugs such as quinine, chloroquine, etc ${ }^{12}$.

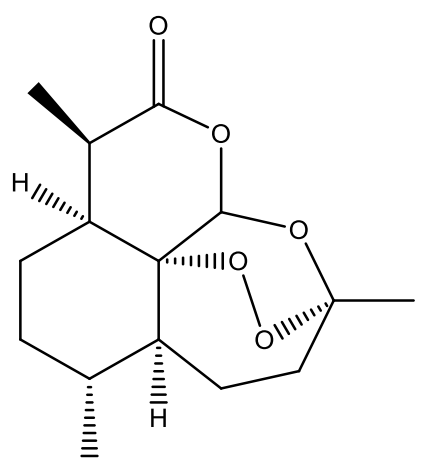

Fig. 4 Artemisinin $^{24}$

Mechanism of working artemisinin: The structure of artemisinin is not like other antimalarial structures which have different working mechanisms. The mechanism of action of this drug is based on the presence of endoperoxide is needed for antimalarial activity. Because peroxide is known as reactive oxygen source species such as hydroxyl radicals and superoxide, the free radicals intensively involved in its mechanism of action. In the mechanism of action of artemisinin derivatives, free radicals showed an important role.

Meshnick and collaborators (1991) proved that artemisinin was intensively interacted with intra-parasitic heme. They also proved that heme or intra-parasitic iron could function of activating parasites of artemisinin into toxic free radicals. Malaria parasites are rich in iron-heme, which originates from host hemoglobin proteolysis. This result was the main reason for an explanation of artemisinin as selective parasites killer $^{25}$. 


\section{Conclusion}

The group of malaria medicines consists of 3, namely: classification of malaria drugs based on the workings of the drug in the Plasmodium life cycle, classification of antimalarial drugs based on the chemical structure of the drug, and classification of antimalarial drugs based on the drug workplace on the subcellular organelles Plasmodium. It is known that chloroquine, pyrimethamine, primaquine, proguanil, doxycycline, tetracycline, sulfadoxine, and artemisia are drugs used in the treatment of malaria.

\section{Acknowledgement}

Thank you to Dr. rer. nat. Anis Yohana Chaerunisaa, M. Si., Apt. and Prof. Dr. Anas Subarnas, M. S., Apt. As a mentor who has provided comments and suggestions for the preparation of this paper.

\section{References}

1. Cui, L., Mharakurwa, S., Ndiaye, D., Rathod, P. K. \& Rosenthal, P. J. 2015. Antimalarial drug resistance: Literature review and activities and findings of the ICEMR network. Am. J. Trop. Med. Hyg 93, 57-68.

2. Chandrashekar, V. N., Kishore Punnath, Kiran K. Dayanand, Rajeshwara N. Achur, Srinivas B. Kakkilaya, Poornima Jayadev, Suchetha N. Kumari, D. Channe Gowda. 2019. Malarial anemia among pregnant women in the south-western coastal city of Mangaluru in India. Informatics Med. Unlocked 15.

3. Cruz-Coke, R. 2016. World Malaria Report. Revista medica de Chile 101, 252-256.

4. Azlin, E. 2017. Obat Anti Malaria. Sari Pediatr 5, 150.

5. Hermanto, F., Iwo, M. I. \& Asih, P. B. S. Thunb. 2013. Terhadap Aktivitas Antimalaria Artemisinin Pada Plasmodium Effect of ethanolic extract of clove (Eugenia caryophylata Thunb) as anti-malaria activity on Plasmodium falciparum 6, 94-99.

6. Muti'ah, R. 2015. Penyakit Malaria Dan Mekanisme Kerja Obat-Obat Antimalaria. Alchemy 2, 80-91.

7. Demissie, Y. \& Ketema, T. 2016. Complicated malaria symptoms associated with Plasmodium vivax among patients visiting health facilities in Mendi town, Northwest Ethiopia. BMC Infect. Dis. 16, 1-8.

8. Fitriany, J. \& Sabiq, A. 2018. Malaria. Jurnal Averrous 4.

9. Nguyen, T. H. Huy Nguyen Tien, Rahul Jain, Kaeko Kamei. 2007. 2-Tert-Butyl-8Quinolinamines Exhibit Potent Blood Schizontocidal Antimalarial Activity Via Inhibition of Heme Crystallization. Antimicrob. Agents Chemother. 51, 2842-2847. 
10. Mungthin, M., Na-Bangchang, K., Tan-Ariya, P., Kongthaisong, M. \& Sinchaipanid, N. 2018. Comparison of the Bioequivalence of Three Oral Formulations of Dihydroartemisinin Based on Ex Vivo Blood Schizontocidal Activities Against Plasmodium Falciparum. Am. J. Trop. Med. Hyg. 71, 703-710.

11. Syamsudin. 2005. Mekanisme Kerja ObatAntimalaria. J. IImu Kefarmasian Indones. 3, 37-40.

12. Simamora, D. \& Enggar Fitri, L. 2017. Resistensi Obat Malaria: Mekanisme Dan Peran Obat Kombinasi Obat Antimalaria Untuk Mencegah. J. Kedokt. Brawijaya 23, 8291.

13. Zhang, J., Ma, W., Xie, B., Gui, J. F. \& Mei, J. 2017. Beneficial effect and potential molecular mechanism of chloroquine on sperm motility and fertilizing ability in yellow catfish. Aquaculture 468, 307-313.

14. Aguiar, A. C. C. Erika Murce, Wilian A. Cortopassi, Andre S. Pimentel, Maria M.F.S. Almeida, Daniele C.S. Barros, Jéssica S. Guedes, Mario R. Meneghetti, Antoniana U. Krettli. 2018. Chloroquine analogs as antimalarial candidates with potent in vitro and in vivo activity. Int. J. Parasitol. Drugs Drug Resist. 8, 459-464.

15. Kementerian Kesehatan RI. 2007. KMK No. 044 ttg Pedoman Pengobatan Malaria.pdf. 1-10.

16. Khatri, P. Mansi K. Shah, Niketkumar Patel, Shashank Jain, Namrata Vora, Senshang Lin. 2018. Preparation and characterization of pyrimethamine solid dispersions and an evaluation of the physical nature of pyrimethamine in solid dispersions. J. Drug Deliv. Sci. Technol. 45, 110-123.

17. Deng, T. Shengjun Wu, Yalan Wu, Shiyou Hu, Huayu Bao, Xin-an Huang, Qin Xu, Zhaoli Yang, Jianping Song, Fang Liu. 2019. An unexpected Griess reaction on the important anti-malarial drug primaquine and its application for drug determination. $J$. Pharm. Biomed. Anal. 171, 8-14.

18. Lochner, M. \& Thompson, A. J. 2014. The Antimalarial Drug Proguanil Is an Antagonist at 5-HT3 Receptors. J. Pharmacol. Exp. Ther. 351, 674-684.

19. Lawrenson, A. S., Cooper, D. L., O'Neill, P. M. \& Berry, N. G. 2018. Study of the antimalarial activity of 4-aminoquinoline compounds against chloroquine-sensitive and chloroquine-resistant parasite strains. J. Mol. Model. 24.

20. Taylor, W. R. H. Widjaja, T. L. Richie, H. Basri, C. Ohrt, Tjitra, E. Taufik, T. R. Jones, K.. 2017. Chloroquine/doxycycline combination versus chloroquine alone, and doxycycline alone for the treatment of Plasmodium falciparum and Plasmodium vivax malaria in northeastern Irian Jaya, Indonesia. Am. J. Trop. Med. Hyg. 64, 223-228. 
21. Peiris-Pagès, M., Sotgia, F. \& Lisanti, M. P. 2015. Doxycycline and therapeutic targeting of the DNA damage response in cancer cells: old drug, new purpose. Oncoscience 2, 696.

22. Chhonker, Y. S. V. V. Bhosale, S. K. Sonkar, H. Chandasana, D. Kumar, S. Vaish, S.C. Choudhary, S. Bhadhuria, S. Sharma, R.K. Singh, G.K. Jain1, A.K. Vaish, S.P.S.Gaur, R. S. Bhatta. 2017. Assessment of Clinical Pharmacokinetic Drug-Drug Interaction of Antimalarial Drugs $\alpha / \beta$-Arteether and Sulfadoxine-Pyrimethamine. Antimicrob. Agents Chemother. 61, 1-25.

23. Aucamp, M., Milne, M. \& Liebenberg, W. 2016. Amorphous Sulfadoxine: A Physical Stability and Crystallization Kinetics Study. AAPS PharmSciTech 17, 1100-1109.

24. Zhang, C. J. Jigang Wang, Jianbin Zhang,Yew Mun Lee,Guangxue Feng, Teck Kwang Lim, Han-Ming Shen, Qingsong Lin, and Bin Liu. 2016. Mechanism-Guided Design and Synthesis of a Mitochondria-Targeting Artemisinin Analogue with Enhanced Anticancer Activity. Angew. Chemie - Int. Ed. 55, 13770-13774.

25. Meshnick, S. R. 2002. Artemisinin: mechanisms of action, resistance and toxicity. 32, 1655-1660. 